Article

\title{
Application of the Response Surface Methodology to Optimize the Fermentation Parameters for Enhanced Docosahexaenoic Acid (DHA) Production by Thraustochytrium sp. ATCC 26185
}

\author{
Kang Wu 1,2, Lijian Ding 1,2,* (D), Peng Zhu ${ }^{1,2}$, Shuang Li ${ }^{2,3}$ and Shan He 1,2,* (D) \\ 1 Li Dak Sum Yip Yio Chin Kenneth Li Marine Biopharmaceutical Research Center, Ningbo University, \\ Ningbo 315211, China; wukang3@163.com (K.W.); zhupeng@nbu.edu.cn (P.Z.) \\ 2 Key Laboratory of Marine Biotechnology of Zhejiang Province, Ningbo University, Ningbo 315211, China; \\ 18857497140@163.com \\ 3 Ningbo Entry-Exit Inspection and Quarantine Bureau Technology Center, Ningbo 315211, China \\ * Correspondence: dinglijian@nbu.edu.cn (L.D.); heshan@nbu.edu.cn (S.H.); Tel.: +86-574-8760-0458 (S.H.)
}

Received: 26 February 2018; Accepted: 18 April 2018; Published: 22 April 2018

\begin{abstract}
The aim of this study was to determine the cumulative effect of fermentation parameters and enhance the production of docosahexaenoic acid (DHA) by Thraustochytrium sp. ATCC 26185 using response surface methodology (RSM). Among the eight variables screened for effects of fermentation parameters on DHA production by Plackett-Burman design (PBD), the initial $\mathrm{pH}$, inoculum volume, and fermentation volume were found to be most significant. The Box-Behnken design was applied to derive a statistical model for optimizing these three fermentation parameters for DHA production. The optimal parameters for maximum DHA production were initial $\mathrm{pH}$ : 6.89, inoculum volume: $4.16 \%$, and fermentation volume: $140.47 \mathrm{~mL}$, respectively. The maximum yield of DHA production was $1.68 \mathrm{~g} / \mathrm{L}$, which was in agreement with predicted values. An increase in DHA production was achieved by optimizing the initial $\mathrm{pH}$, fermentation, and inoculum volume parameters. This optimization strategy led to a significant increase in the amount of DHA produced, from $1.16 \mathrm{~g} / \mathrm{L}$ to $1.68 \mathrm{~g} / \mathrm{L}$. Thraustochytrium sp. ATCC 26185 is a promising resource for microbial DHA production due to the high-level yield of DHA that it produces, and the capacity for large-scale fermentation of this organism.
\end{abstract}

Keywords: Thraustochytrium; docosahexaenoic acid (DHA); Plackett-Burman designs; response surface methodology

\section{Introduction}

Docosahexaenoic acid (DHA) plays a significant role as a nutrient required by both invertebrates and vertebrates. Since DHA is indispensable for prenatal and postnatal development of visual and other perceptive functions, this compound is added to many infant dietary formulas [1,2]. Additionally, it has been observed that DHA is correlated with enhanced quality of life and reduced risk of cardiovascular and neurological diseases [3].

Mammals lack the enzymes required to produce DHA de novo, so this substance must be obtained through the diet. A variety of marine fish species are currently the primary commercial sources of DHA. However, fish-derived DHA is associated with many shortcomings, including unstable quality, a fishy odor, environmental pollution, high processing costs and a tendency to oxidize $[4,5]$. Accordingly, efforts have been made to divert commercial DHA production towards the exploitation of oleaginous microorganisms that biosynthesize DHA, such as thraustochytrids 
and marine diatoms [6]. Thraustochytrium, unicellular eukaryotic marine protists, have been isolated mainly from coastal marine environments [7]. Thraustochytrium strains have attracted attention from researchers worldwide, since these can build dense biomass in culture and produce polyunsaturated fatty acids (PUFAs), especially those from the omega-3 series, such as DHA [8]. Therefore, some Thraustochytrium strains are considered to be prospective alternatives to marine fish oils as new sources of DHA for use in aquaculture products and food additives.

To optimize DHA production, several chemical parameters, including carbon and nitrogen sources at different concentrations, as well as physical parameters, including initial $\mathrm{pH}$ and inoculum age, must be considered [9]. It was observed that thraustochytrids isolated from different environments also have variant DHA production levels [10,11]. The fermentation conditions must, furthermore, have a decisive role in regulating the DHA production of thraustochytrids [12]. With the aim of high DHA productivity, a temperature shift regime resulted in a DHA content of $52 \%$ of total fatty acids. A decline in temperature from $30{ }^{\circ} \mathrm{C}$ to $20^{\circ} \mathrm{C}$ yielded high levels of DHA, making $30{ }^{\circ} \mathrm{C}$ the optimal culture temperature for the highest biomass growth [13]. Glucose and glycerol are used as a mixed carbon source for Aurantiochytrium limacinum SR21, and DHA productivity was $15.24 \%$ higher than that obtained using glucose as a single carbon source [14]. The continuous culture method was carried out to feed A. limacinum SR21, whereby the yield of biomass was $11.78 \mathrm{~g} / \mathrm{L}$ and DHA concentration reached $1.74 \mathrm{~g} / \mathrm{L}$ [15]. Response surface methodology (RSM) is known to be effective for the optimization of multiple factors for fermentation yields [16]. The empirical model developed by RSM was adequate to ascertain the possible interactions between the studied parameters and the response of DHA production. For example, RSM was previously used in optimizing significant fermentation variables (glucose concentration, yeast extract addition, $\mathrm{NaCl}$ content, $\mathrm{pH}$, and incubation time), leading to a maximum DHA concentration of $516 \mathrm{mg} / \mathrm{L}$ by Schizochytrium sp. S31 [17].

This work attempts to optimize the fermentation parameters in the cultivation of Thraustochytrium sp. so that it may enhance the DHA yield. The influence of fermentation parameters on the production of DHA were investigated through the Box-Behnken design of experiments.

\section{Results}

\subsection{Optimization of Culture Conditions by RSM}

Plackett-Burman design methods can be used in the screening of the key influential factors compared with other statistical designs on the experimental response. Eight variables were selected in the screening approach with Plackett-Burman experimental design, suggesting 12 trial runs. The production of DHA was selected as the observed response to determine the effects of the variables studied. Table 1 shows the experimental parameters investigated and the levels of each used in the experimental design, whereas the design matrix is shown in Table 2. Pareto analysis was used to determine the contribution of the screened variables (Figure 1), which showed that the initial $\mathrm{pH}$ had the highest positive effect on DHA production, followed by inoculum volume, and fermentation volume. These three factors were determined to be of the highest relative importance that influence DHA production compared with the other fermentation parameters tested and, hence, each was selected for further optimization.

Table 1. Factors and experimental domain for the screening with Plackett-Burman design.

\begin{tabular}{cccc}
\hline Factors & Associated Variable & Low Level (-1) & High Level (+1) \\
\hline Glucose $(\mathrm{g} / \mathrm{L})$ & $X_{1}$ & 40 & 60 \\
Yeast extract $(\mathrm{g} / \mathrm{L})$ & $X_{2}$ & 8 & 12 \\
Sea salt $(\mathrm{g} / \mathrm{L})$ & $X_{3}$ & 20 & 30 \\
Fermentation volume $(\mathrm{mL})$ & $X_{4}$ & 200 & 300 \\
Inoculum volume $(\%)$ & $X_{5}$ & 7 & 10 \\
Temperature $\left({ }^{\circ} \mathrm{C}\right)$ & $X_{6}$ & 25 & 30 \\
\hline
\end{tabular}


Table 1. Cont.

\begin{tabular}{cccc}
\hline Factors & Associated Variable & Low Level (-1) & High Level (+1) \\
\hline Initial $\mathrm{pH}$ & $X_{7}$ & 6 & 8 \\
Agitation $(\mathrm{rpm})$ & $X_{8}$ & 150 & 200 \\
\hline
\end{tabular}

Table 2. Plackett-Burman design for screening variables (in coded level) with DHA production as the response.

\begin{tabular}{cccccccccc}
\hline Runs & $\boldsymbol{X}_{\mathbf{1}}$ & $\boldsymbol{X}_{\mathbf{2}}$ & $\boldsymbol{X}_{\mathbf{3}}$ & $\boldsymbol{X}_{\mathbf{4}}$ & $\boldsymbol{X}_{\mathbf{5}}$ & $\boldsymbol{X}_{\mathbf{6}}$ & $\boldsymbol{X}_{\mathbf{7}}$ & $\boldsymbol{X}_{\mathbf{8}}$ & DHA (g/L) \\
\hline 1 & 1 & 1 & -1 & -1 & -1 & 1 & -1 & 1 & 0.890 \\
2 & 1 & -1 & 1 & 1 & 1 & -1 & -1 & -1 & 0.263 \\
3 & 1 & 1 & 1 & -1 & -1 & -1 & 1 & -1 & 0.494 \\
4 & -1 & -1 & -1 & 1 & -1 & 1 & 1 & -1 & 0.407 \\
5 & -1 & -1 & -1 & -1 & -1 & -1 & -1 & -1 & 0.706 \\
6 & 1 & -1 & -1 & -1 & 1 & -1 & 1 & 1 & 0.318 \\
7 & -1 & 1 & 1 & -1 & 1 & 1 & 1 & -1 & 0.382 \\
8 & -1 & 1 & 1 & 1 & -1 & -1 & -1 & 1 & 0.742 \\
9 & -1 & -1 & 1 & -1 & 1 & 1 & -1 & 1 & 0.722 \\
10 & -1 & 1 & -1 & 1 & 1 & -1 & 1 & 1 & 0.359 \\
11 & 1 & 1 & -1 & 1 & 1 & 1 & -1 & -1 & 0.401 \\
12 & 1 & -1 & 1 & 1 & -1 & 1 & 1 & 1 & 0.363 \\
\hline
\end{tabular}

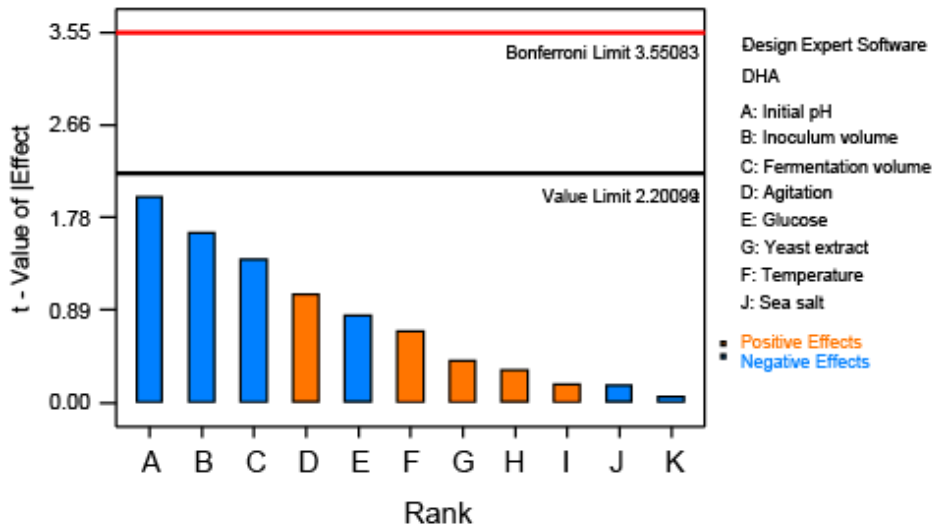

Figure 1. Pareto chart of each factor standard effects on DHA production.

\subsection{Optimization of Fermentation Parameters by BBD}

The most important parameters determined in this study by Plackett-Burman design experiments for the efficiency of DHA production were fermentation volume, inoculum volume, and initial $\mathrm{pH}$. In order to study the combined effect of these factors, secondary experiments were performed with different combinations of the parameters. The range of values for the input variables is shown in Table 3. Trial runs were planned to obtain a quadratic model consisting of 12 trials plus center points. Thus with the aim of assessing the combined effect of these factors, 17 experiments were performed for different combinations of the parameters using statistically designed experiments. The design matrix of the parameters in coded units is listed in Table 4, along with the predicted and experimental values of response. The final regression equation in terms of coded factors was evaluated by Design-expert software, which yielded Equation (1) below:

$$
\begin{aligned}
Y_{D H A}=1.22-0.21 X_{1} & +0.071 X_{2}+0.092 X_{3}-0.046 X_{1} X_{2}-0.099 X_{1} X_{3}-0.036 X_{2} X_{3} \\
& +3.463 \times 10^{-4} X_{1}^{2}+0.16 X_{2}^{2}+0.14 X_{3}^{2}
\end{aligned}
$$


In Equation (1), $Y$ is the predicted response of DHA production, $X_{1}, X_{2}$, and $X_{3}$ are the coded values of the test variables, fermentation volume $(\mathrm{mL})$, inoculum volume $(\%)$, and initial $\mathrm{pH}$, respectively. The statistical significance of Equation (1) was checked by the F-test, and the analysis of variance (ANOVA) for response surface quadratic model is summarized in Table 5.

Table 3. Experimental ranges and levels in the experimental design.

\begin{tabular}{cccc}
\hline \multirow{2}{*}{ Factors } & \multicolumn{3}{c}{ Range and Level } \\
\cline { 2 - 4 } & $\mathbf{- 1}$ & $\mathbf{0}$ & $\mathbf{+ 1}$ \\
\hline$X_{1}$ : Fermentation volume $(\mathrm{mL})$ & 140 & 180 & 220 \\
$X_{2}:$ Inoculum volume $(\%)$ & 4 & 5 & 6 \\
$X_{3}$ : Initial $\mathrm{pH}$ & 6 & 6.5 & 7 \\
\hline
\end{tabular}

Table 4. The Box-Behnken design matrix for coded variables along with actual and predicted responses.

\begin{tabular}{ccccccc}
\hline & & & & \multicolumn{3}{c}{ DHA (g/L) } \\
\cline { 5 - 7 } Run & $\boldsymbol{X}_{\mathbf{1}}$ & $\boldsymbol{X}_{\mathbf{2}}$ & $\boldsymbol{X}_{\mathbf{3}}$ & Actual Response & Predicted Response & Residual \\
\hline 1 & 0 & 0 & 0 & 1.17 & 1.22 & -0.058 \\
2 & -1 & -1 & 0 & 1.54 & 1.48 & 0.068 \\
3 & 0 & 0 & 0 & 1.14 & 1.22 & -0.081 \\
4 & 1 & 0 & -1 & 1.22 & 1.16 & 0.057 \\
5 & -1 & 0 & 1 & 1.71 & 1.77 & -0.057 \\
6 & 0 & 0 & 0 & 1.22 & 1.22 & $5.800 \times 10^{-4}$ \\
7 & 0 & 1 & -1 & 1.55 & 1.54 & 1.55 \\
8 & 0 & -1 & 1 & 1.57 & 1.58 & -0.011 \\
9 & 1 & 0 & 1 & 1.15 & 1.15 & $7.112 \times 10^{-4}$ \\
10 & 0 & 1 & 1 & 1.72 & 1.65 & 0.067 \\
11 & 0 & -1 & -1 & 1.26 & 1.33 & -0.067 \\
12 & 0 & 0 & 0 & 1.22 & 1.22 & $-8.220 \times 10^{-3}$ \\
13 & 1 & -1 & 0 & 1.16 & 1.15 & $9.994 \times 10^{-3}$ \\
14 & -1 & 0 & -1 & 1.39 & 1.39 & $-7.112 \times 10^{-4}$ \\
15 & 1 & 1 & 0 & 1.13 & 1.20 & -0.068 \\
16 & -1 & 1 & 0 & 1.70 & 1.71 & $-9.994 \times 10^{-3}$ \\
17 & 0 & 0 & 0 & 1.37 & 1.22 & 0.15 \\
\hline
\end{tabular}

Table 5. ANOVA results of quadratic model for DHA production $\left(R^{2}=0.9210\right.$; Pred $R^{2}=0.7290$; $\left.\operatorname{Adj} R^{2}=0.8559 ; C V \%=6.58\right)$.

\begin{tabular}{ccccccc}
\hline Source & SS & $d f$ & MS & $\boldsymbol{F}$-Value & Prob $>\boldsymbol{F}$ & \\
\hline Model & 0.72 & 9 & 0.08 & 9.93 & 0.0031 & significant \\
$X_{1}$ & 0.36 & 1 & 0.36 & 44.21 & 0.0003 & \\
$X_{2}$ & 0.04 & 1 & 0.04 & 5 & 0.0604 & \\
$X_{3}$ & 0.067 & 1 & 0.067 & 8.34 & 0.0234 & \\
$X_{1} X_{2}$ & $8.46 \times 10^{-3}$ & 1 & $8.46 \times 10^{-3}$ & 1.05 & 0.34 & \\
$X_{1} X_{3}$ & 0.039 & 1 & 0.039 & 4.88 & 0.063 & \\
$X_{2} X_{3}$ & $5.08 \times 10^{-3}$ & 1 & $5.08 \times 10^{-3}$ & 0.63 & 0.4537 & \\
$X_{1}^{2}$ & $5.05 \times 10^{-7}$ & 1 & $5.05 \times 10^{-7}$ & $6.25 \times 10^{-5}$ & 0.9939 & \\
$X_{2}^{2}$ & 0.11 & 1 & 0.11 & 13.07 & 0.0086 & \\
$X_{3}^{2}$ & 0.086 & 1 & 0.086 & 10.7 & 0.0136 & \\
Residual & 0.057 & 7 & $8.08 \times 10^{-3}$ & & & \\
Lack of Fit & 0.025 & 3 & $8.44 \times 10^{-3}$ & 1.08 & 0.4516 & not significant \\
Pure Error & 0.031 & 4 & $7.80 \times 10^{-3}$ & & & \\
Cor Total & 0.78 & 16 & & & & \\
\hline
\end{tabular}

$\mathrm{SS}$, sum of squares; $d f$, degrees of freedom; MS, mean square.

The three-dimensional response surface plots generated from BBD experiments are the graphical representations of the regression equation, and these plots are shown in Figure 2. The main goal of 
RSM is to efficiently track the optimum values of the process parameters such that the response is maximized. Software-based numerical optimization of the overall desirability function was carried out to find the optimal response within the specified ranges of the variables in the optimization of fermentation for DHA production. The predicted optimal values for the parameters were as follows: fermentation volume, $X_{1}=140.47 \mathrm{~mL}$, inoculation volume, $X_{2}=4.16 \%$, and initial $\mathrm{pH}, X_{3}=6.89$. To confirm the validity of predicted response, three successive experiments were conducted using the optimized parameters, and the statistical model and regression equation were validated and adequate. The average amount of biomass obtained in these experimental runs was $15.01 \mathrm{~g} / \mathrm{L}$. The obtained DHA production from the optimized condition was $1.68 \mathrm{~g} / \mathrm{L}$, near to the predicted result of $1.77 \mathrm{~g} / \mathrm{L}$.
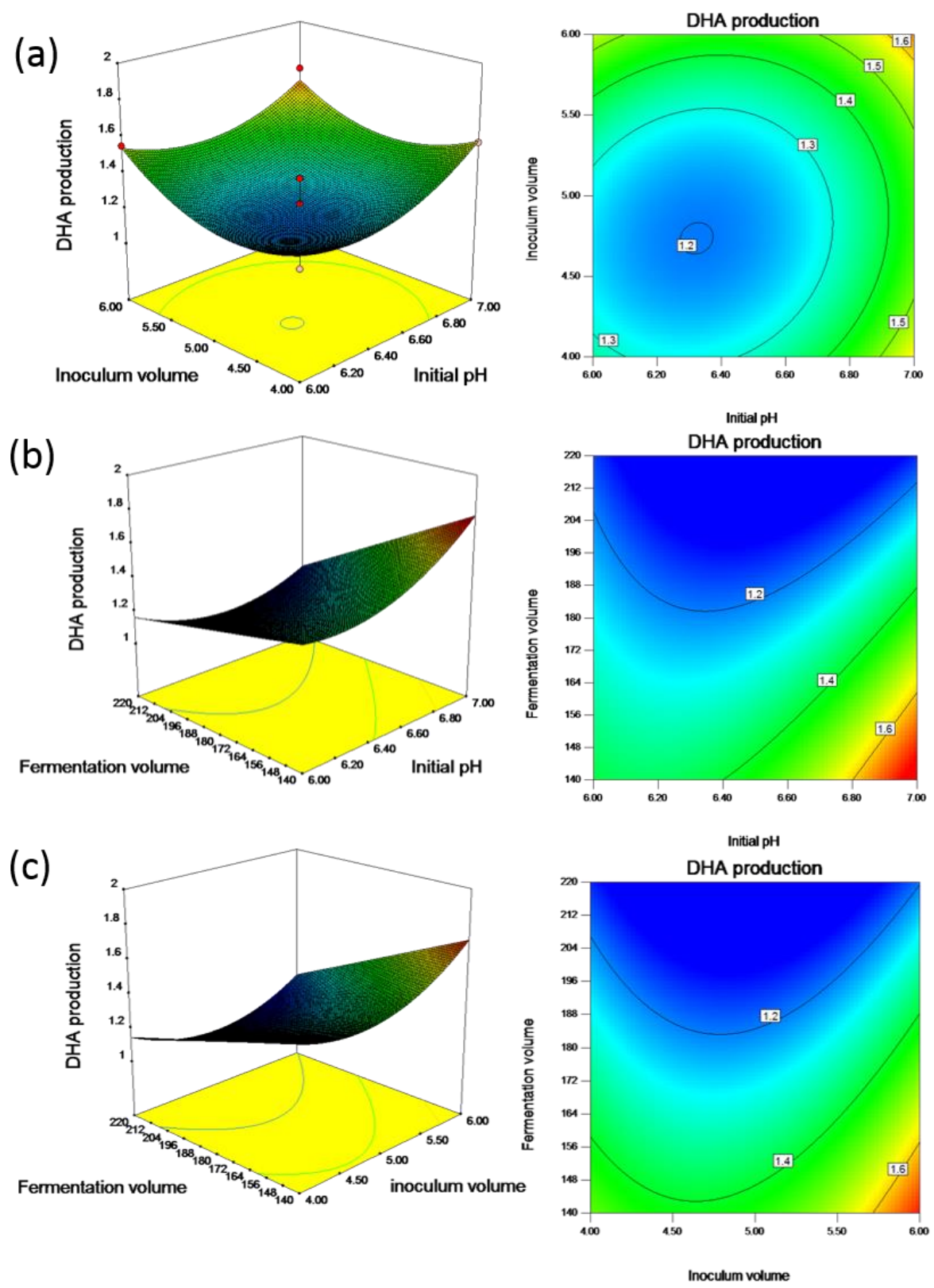

Figure 2. Response surfaces and corresponding contours of DHA production in terms of interaction between $(\mathbf{a})$ inoculum volume $(\mathrm{mL})$ and initial $\mathrm{pH}$; $(\mathbf{b})$ fermentation volume $(\mathrm{mL})$ and initial $\mathrm{pH}$; and $(\mathbf{c})$ fermentation volume $(\mathrm{mL})$ and inoculum volume $(\mathrm{mL})$. 


\section{Discussion}

Response surface methodology is suitable for processes optimization for many industrial products, including paints and coatings, foods and beverages, and pharmaceuticals. Compared with one-factor-at-a-time experiments, statistically designed experiments are able to describe the effect of the interactions among the factors in linear and quadratic terms. In the present study, the optimization of DHA production by Thraustochytrium sp. ATCC 26185 was divided into two phases: a screening of main effects of the selected variables and a response optimization. Reduction in the initial number of variables was carried out through Plackett-Burman design and, among eight tested variables, the initial $\mathrm{pH}$, inoculum volume, and fermentation volume were taken for BBD of RSM to assess their effects on DHA production by Thraustochytrium sp. ATCC 26185.

A large model $F$-value indicates that most of the variation in the response can be explained by a given regression equation. The ANOVA result for DHA production by Thraustochytrium sp. ATCC 26185 in this study showed an F-value of 9.93, which indicated that the terms in the model had a significant effect on the response. The probability $p$-value of 0.0031 for DHA production reinforced that the model terms are statistically significant at the $95 \%$ confidence level. The results of ANOVA also provide a term for residual error, which measures the amount of variation in the response data that was left unexplained by the model. In the present study, the $R^{2}$ and Adj $R^{2}$ values for DHA production were 0.9210 and 0.8559 , respectively. It can, thus, be understood that at least $7 \%$ of the experimental results were not explained by the proposed model. The predicted $R^{2}$ is the measure of the variation in data explained by the model. The "Pred $R^{2}$ " of 0.7290 was in reasonable agreement

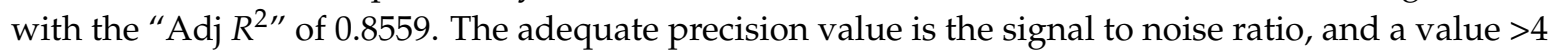
is desirable in support of the fitness of the model [18]. The ratio determined of 9.047 indicated an adequate signal, suggesting that these models can be used to navigate the design space (Figure 3).

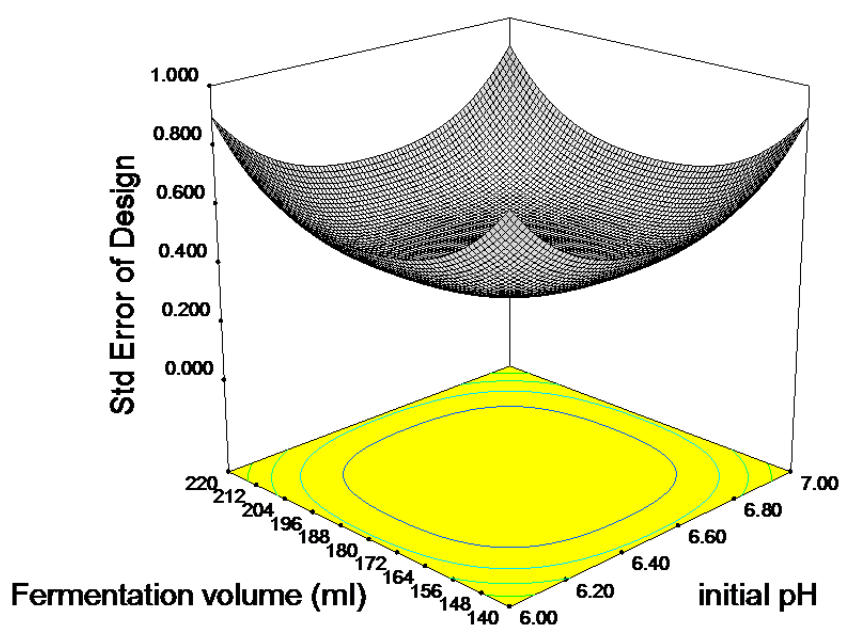

Figure 3. Three-dimensional standard error plot of the model holding initial $\mathrm{pH}$ and fermentation volume.

The ratio of triacylglycerols to phospholipids, as well as the fatty acid profile of Thraustochytrium is known to depend on culture conditions [19]. The optimization of culture conditions ( $\mathrm{pH}$, dissolved oxygen, and temperature) led to a significant increase in the amount of eicosapentaenoic acid (EPA) produced by marine bacteria, where the amount of EPA increased from $33 \mathrm{mg} / \mathrm{L}$ to $350 \mathrm{mg} / \mathrm{L}$ [20]. Production of EPA comprises biomass producing and lipid generating stages. During the first phase, the biomass is increased by supplying carbon and nitrogen. In the second phase, carbon alone is supplied to enhance lipid levels. Accumulation of DHA in the form of triacylglycerols or neutral lipids is important for these protists. It was observed that neutral and polar lipids were produced in equal amounts in the early growth phase in Schizochytrium sp. strain SR21 and microalgae, but on further cell growth only the neutral lipids increased [21]. The DHA content among total fatty acids was only $8.7 \%$ 
in mature cells of S. limacinum SR21 compared to $62 \%$ in young ones, suggesting the transfer of the fatty acids of polar lipids to neutral lipids [22]. The biological significance of DHA in thraustochytrid cells was studied to show that DHA is conserved in the form of fatty acid energy reserves and utilized during starvation [23]. A decline in total lipids was observed with the extension in the starvation phase. Therefore, obtaining the maximum possible biomass with a high amount of total lipids in the shortest possible time is recommended for the strategy in development for DHA production. In this study, the inoculum volume was manipulated for biomass growth and lipid accumulation to reach the stationary phase. It was found that inoculum volume and initial $\mathrm{pH}$ interacted negatively, with a coincident decrease in both of these variables resulting in an increase in DHA production. As shown in Figure 2a, the pattern of the effect of inoculum volume on DHA can be visualized using a three-dimensional response surface plot and corresponding contour plot, and the production of DHA increased as the inoculum volume increased. The size of the inoculum obviously plays a significant role in the growth phase. This likely occurred because the increase in inoculum sizes manipulated microbial growth and lipid biosynthesis, whereas excessive inoculation led to the shortening of the fermentation cycle. The results also showed that an appropriate inoculum volume and initial $\mathrm{pH}$ enhanced the production of DHA.

The $p$-value of each variable shown in Table 5 show that the fermentation volume in flasks was the most significant growth factor affecting the growth and DHA production. The increase in the amount of liquid volume in the shake flask could cause the dissolved oxygen to decrease, which inhibits cell growth. It has been reported that the transformation of saturated fatty acids into unsaturated fatty acids occurred when oil-producing strains grow in oxygen-abundant environments [24]. The volume of the liquid medium was also noted that DO was affected, thus resulting in a lower DHA yield [25]. A large volume of liquid medium (more than $40 \mathrm{~mL}$ in a $250 \mathrm{~mL}$ flask) can also lead to a low DHA yield [16]. The effect of fermentation volume on DHA production may be partially due to the fact that the solubility of oxygen significantly increases at lower liquid volume, which may lead to a relatively higher production of DHA. The higher level of DHA observed at higher DO may be due to the enhanced biosynthesis of DHA as a response to a high DO concentration in the surrounding environment. It has been reported that a stepwise aeration control strategy was adopted for Schizochytrium sp., whereby biomass reached $71 \mathrm{~g} / \mathrm{L}$ and total fatty acids reached $35.75 \mathrm{~g} / \mathrm{L}$ [26]. It was also observed that a DHA concentration, DHA productivity, and conversion yield of $28.93 \mathrm{~g} / \mathrm{L}, 301 \mathrm{mg} / \mathrm{L} / \mathrm{h}$, and $0.44 \pm 0.02 \mathrm{~g} / \mathrm{g}$, respectively, by Schizochytrium sp. S31 under constantly high oxygen transfer conditions [27]. Thus, obtaining high amounts of DHA requires a higher level of DO.

Table 5 indicates that the interaction between the fermentation volume and initial $\mathrm{pH}$ has a significant effect on DHA production, whereas the quadratic effect of $\mathrm{pH}$ had a significant impact on the amount of biomass and DHA production. Figure $3 \mathrm{~b}$ shows the three-dimensional response surface plot for this interaction. From this figure, it can be deduced that providing high levels of fermentation volume and low levels of $\mathrm{pH}$ has a negative effect on DHA. Thus, to obtain high amounts of DHA, either one of these factors must be kept at a low level while maintaining the other factor at a high level. The effect alters permeation of ions, acids and bases into the cell, and affects the biochemical metabolism. It was previously found that DHA formation was slightly affected by medium $\mathrm{pH}$ with the highest DHA proportion of total fatty acids at pH 7.2 in Crypthecodinium cohnii, whereas the saturated fatty acids proportion of total fatty acids at this $\mathrm{pH}$ value were the lowest [28]. The production of lipid and DHA by Schizochytrium sp. S31 incubated at initial pH levels of 5.0 and 6.0 was low. An initial pH of 8.0 for cultivation was too basic for growth and there was a high level of residual glucose, $16 \mathrm{~g} / \mathrm{L}$, in the medium after four days of cultivation [17].

To date, numerous studies have been conducted to enhance DHA production of Thraustochytrium using various modes of fermentation and strategic techniques. In an attempt to enhance DHA production by Thraustochytrium sp. ATCC 26185, Furlan et al. performed the conventional one-factor-at-a-time optimization, and the experiment showed the highest DHA yield (1.16 g/L) using different glucose and nitrogen concentrations [29,30]. In comparison, this isolate produced $1.68 \mathrm{~g} / \mathrm{L}$ 
in the current study using the more sophisticated statistical design of experiments in shake-flask, which was $45 \%$ higher than prior to optimization.

\section{Materials and Methods}

\subsection{Microorganisms and Culture Conditions}

Thraustochytrium sp. ATCC 26185 was purchased from the American Type Culture Collection (Manassas, VA, USA). An extract produced from Thraustochytrium sp. ATCC 26185 was previously shown to contain high amounts of lipids, up to $32 \%$ of the biomass, and DHA comprised as much as $25 \%$ of the total fatty acid content [31]. This organism was maintained at room temperature on GYP agar plates containing $4 \mathrm{~g} / \mathrm{L}$ glucose, $2 \mathrm{~g} / \mathrm{L}$ yeast extract, $2 \mathrm{~g} / \mathrm{L}$ peptone, $30 \mathrm{~g} / \mathrm{L}$ artificial seawater salt, and $15 \mathrm{~g} / \mathrm{L}$ agar. The single colonies from a plate culture were inoculated into $50 \mathrm{~mL}$ seeding broth (in $250 \mathrm{~mL}$ flask) containing $40 \mathrm{~g} / \mathrm{L}$ glucose, $5 \mathrm{~g} / \mathrm{L}$ yeast extract, $5 \mathrm{~g} / \mathrm{L}$ peptone, and $30 \mathrm{~g} / \mathrm{L}$ sea salt, then were grown at $28{ }^{\circ} \mathrm{C}$ on a shaker incubator with $200 \mathrm{rpm}$ agitation.

\subsection{Experimental Design: Plackett-Burman Design}

Plackett-Burman design is applied to evaluate the relative importance of several fermentation parameters that influence the desired response, and enables one to screen $\mathrm{N}$ variables in at least $\mathrm{N}+1$ experiments [32]. To increase the response, each factor selected was tested in two levels, high $(+1)$ and low (-1). A Plackett-Burman design of the experiments was formulated for eight factors using the Design-Expert version 8.0 software (Stat-Ease, Inc., Minneapolis, MN, USA). For the present study, the selected factors included the levels of glucose, yeast extract and sea salt, fermentation volume, inoculum volume (mid-exponential phase), temperature, initial $\mathrm{pH}$, and agitation rate. The levels of each factor were determined based on prior experience. The effect of each variable was estimated from by Equation (2), as follows:

$$
E(x i)=\frac{\sum M_{i}^{+}-\sum M_{i}^{-}}{\mathrm{N}}
$$

where $\sum M_{i}^{+}$and $\sum M_{i}^{-}$are the sum of the responses for which variable $X i$ is in the high level $(X i=+1)$ and the low level $(X i=-1)$, respectively. In this equation, $\mathrm{N}$ is the total number of trials conducted.

Each trial run was performed in triplicate, and the average of DHA production from Thraustochytrium sp. ATCC 26185 was taken as the response. Pareto chart analysis was used to evaluate the variables, which presents the impact of each variable on DHA production, and the most significant variables were further investigated by Box-Behnken design of response surface methodology.

\subsection{Experimental Design: Box-Behnken Design}

It is possible to derive an expression for an overall performance measure based on the response values obtained from experiments at particular combinations of input variables [33]. Box-Behnken design (BBD) was performed to ascertain the main effects of the parameters studied, the interactions among them and the quadratic effect for the responses. A three-level, three-factorial BBD system was used to investigate and validate the fermentation parameters affecting production of DHA by Thraustochytrium sp. ATCC 26185. To evaluate the influence of significant factors, three independent variables were chosen after Pareto analysis of the Plackett-Burman experimental results: fermentation volume, inoculum volume and initial $\mathrm{pH}$. The ranges of variables were assigned based on path of steepest ascent [34]. A total of 17 experiments were conducted based on the output of Design Expert software.

The numbers of experiments were calculated as $\mathrm{N}$ in Equation (3), as follows:

$$
N=k^{2}+k+n_{0}
$$


In Equation (3), $k$ is the variable number and $n_{0}$ is the number of the center point. Quadratic and interaction effects of the independent variables were evaluated for RSM. The sequential F-test, lack-of-fit test and other adequacy measures were used in selecting the best model [35]. The relationship between the response and the input process parameters were performed by using Equation (4):

$$
\mathrm{Y}=f\left(x_{1}+x_{2}, \ldots, x_{n}\right)+\varepsilon
$$

In Equation (4), $f$ is the real response function its format being unknown, and $\varepsilon$ is the residual error which describes the differentiation that can be included by the function $f$. In consideration of the linear terms, square terms and linear interaction items, the second order equation response was modeled by Equation (5) to correlate the dependent and independent variables, as follows:

$$
\mathrm{Y}=\beta_{0}+\sum \beta_{i} x_{i}+\sum \beta_{i i} x_{i i}^{2}+\sum \beta_{i j} x_{i} x_{j}+\varepsilon
$$

In Equation (5), $\mathrm{Y}$ is the predicted response, $\beta_{0}$ is the model constant, $\beta_{i}$ is the regression coefficient for the input factor $x_{i}, \beta_{i i}$ is the regression coefficient for interactions, and $\beta_{i j}$ is the regression coefficient for square effects between the input factor $x_{i}$ and $x_{j}$. The optimum values of the selected variables were determined by solving the regression equation and analyzing the three-dimensional surface plots. A fermentation experiment was employed to evaluate the DHA production of Thraustochytrium sp. ATCC 26185 using the predicted optimum parameter values.

\subsection{Fatty Acid Methyl Ester Extraction, Preparation, and Analysis}

Dried cells (20 mg) were suspended in $1.5 \mathrm{~mL}$ methanol/acetyl chloride (10:1, v/v), $1 \mathrm{~mL}$ of hexane and $15 \mu \mathrm{g}$ nonadecanoic acid were added and heated at $70^{\circ} \mathrm{C}$ for $2 \mathrm{~h}$ in sealed tubes. After cooling, $2.5 \mathrm{~mL} 6 \% \mathrm{~K}_{2} \mathrm{CO}_{3}$ and $1 \mathrm{~mL}$ hexane were then added to the extracts, the mixture shaken, centrifuged, and the upper layer separated.

The profiling of extracted FAMEs was performed by GC-MS with a SPB-50 fused silica capillary column, $30 \mathrm{~m} \times 0.25 \mathrm{~mm} \times 0.25 \mu \mathrm{m}$ (Supelo, Bellefonte, PA, USA) installed in a QP2010 GC equipped with an AOC-20 autosampler (Shimadzu, Kyoto, Japan) and mass spectrometer (Shimadzu, Kyoto, Japan). The temperature of the injector was set to $250{ }^{\circ} \mathrm{C}$. High-purity helium was used as the carrier gas, with a column flow rate of $0.81 \mathrm{~mL} \mathrm{~min}^{-1}$ and a pre-column pressure of $73.0 \mathrm{kPa}$. After injection, the oven temperature was kept at $150{ }^{\circ} \mathrm{C}$ for $3.5 \mathrm{~min}$, increased at $20^{\circ} \mathrm{C} / \mathrm{min}$ to $200{ }^{\circ} \mathrm{C}$, held for $5 \mathrm{~min}$, then increased at $5^{\circ} \mathrm{C} / \mathrm{min}$ to a final temperature of $280^{\circ} \mathrm{C}$, where it was held for $30 \mathrm{~min}$. The sample injection volume was $1 \mu \mathrm{L}$ with a split ratio of 50:1. The MS was operated in electron impact (EI) mode with an electron energy of $70 \mathrm{eV}$. Furthermore, the source temperature was set at $200{ }^{\circ} \mathrm{C}$, and the transfer line temperature was $250{ }^{\circ} \mathrm{C}$. The mass spectrometer was set to scan from $\mathrm{m} / \mathrm{z} 50$ to 600 . There was a 3.5 min solvent delay time. Nonadecanoic acid (C19:0) (Sigma Aldrich, Dorset, UK) was used as an internal standard and its peak area was used to determine the amount of each fatty acid based on the areas of all peaks and the known concentration of the standard added.

\section{Conclusions}

In conclusion, the DHA production was optimized applying BBD under response surface methodology by fitting a second-order model to the response data. The optimized parameters for enhanced DHA accumulation by Thraustochytrium sp. ATCC 26185 was mostly close to the predicted values. Under cultivation using the determined optimal medium, the predicted value of DHA production yield was $1.77 \mathrm{~g} / \mathrm{L}$ and the measured experimental value was $1.68 \mathrm{~g} / \mathrm{L}$ in a shake-flask. Microbial DHA can be extracted and supplied to the food and pharmaceutical industries using this cultivation method, or the microbial biomass could be directly introduced as poultry feed and as a fish supplement in aquaculture. 
Acknowledgments: This work was funded by the Ningbo Sci and Tech Project for Common Wealth (2015C10026, 2017C10016), the National Natural Science Foundation of China $(41776168,41706167)$, the Science and Technology Project of AQSIQ (no. 2016IK169), the Zhejiang Provincial Basic Public Welfare Research Project (2015IK226, LGN18B050002), the National 111 Project of China (D16013), the Li Dak Sum Yip Yio Chin Kenneth Li Marine Biopharmaceutical Development Fund, and the K.C. Wong Magna Fund in Ningbo University. We thank C. Benjamin Naman of Ningbo University for careful editing of, and thoughtful comments about, the manuscript.

Author Contributions: K.W., L.D., P.Z., and S.H. conceived and designed the experiments; K.W. performed the experiments; K.W., S.L., and L.D. analyzed the data; and K.W. and L.D. wrote the paper.

Conflicts of Interest: The authors declare no conflict of interest.

\section{Abbreviations}

$\begin{array}{ll}\text { DHA } & \text { Docosahexaenoic acid } \\ \text { RSM } & \text { Response surface methodology } \\ \text { BBD } & \text { Box-Behnken Design } \\ \text { ANOVA } & \text { Analysis of variance } \\ \text { DO } & \text { Dissolved oxygen }\end{array}$

\section{References}

1. Birch, E.E.; Garfield, S.; Castañeda, Y.; Hughbanks-Wheaton, D.; Uauy, R.; Hoffman, D. Visual acuity and cognitive outcomes at 4 years of age in a double-blind, randomized trial of long-chain polyunsaturated fatty acid-supplemented infant formula. Early Hum. Dev. 2007, 83, 279-284. [CrossRef] [PubMed]

2. Innis, S.M. Dietary omega 3 fatty acids and the developing brain. Brain Res. 2008, 1237, 35-43. [CrossRef] [PubMed]

3. Masson, S.; Latini, R.; Tacconi, M.; Bernasconi, R. Incorporation and washout of n-3 polyunsaturated fatty acids after diet supplementation in clinical studies. J. Cardiovasc. Med. 2007, 8 (Suppl. 1), S4-S10. [CrossRef]

4. Hooper, L.; Smith, G.D. Risks and benefits of omega 3 fats for mortality, cardiovascular disease, and cancer: Systematic review. BMJ 2006, 332, 752-760. [CrossRef] [PubMed]

5. Gupta, A.; Barrow, C.J.; Puri, M. Omega-3 biotechnology: Thraustochytrids as a novel source of omega-3 oils. Biotechnol. Adv. 2012, 30, 1733-1745. [CrossRef] [PubMed]

6. Yokochi, T.; Honda, D.; Higashihara, T.; Nakahara, T. Optimization of docosahexaenoic acid production by Schizochytrium limacinum SR21. Appl. Microbiol. Biotechnol. 1998, 49, 72-76. [CrossRef]

7. Kimura, H.; Fukuba, T.; Naganuma, T. Biomass of thraustochytrid protoctists in coastal water. Mar. Ecol. Prog. Ser. 1999, 189, 27-33. [CrossRef]

8. Bajpai, P.; Bajpai, P.K.; Ward, O.P. Production of docosahexaenoic acid by Thraustochytrium aureum. Appl. Microbiol. Biotechnol. 1991, 35, 706-710. [CrossRef]

9. Bajpai, P.K.; Bajpai, P.; Ward, O.P. Optimization of production of docosahexaenoic acid (DHA) by Thraustochytrium aureum ATCC 34304. J. Am. Oil Chem. Soc. 1991, 68, 509-514. [CrossRef]

10. Huang, J.; Aki, T.; Yokochi, T.; Nakahara, T.; Honda, D.; Kawamoto, S.; Shigeta, S.; Ono, K.; Suzuki, O. Grouping newly isolated docosahexaenoic acid-producing thraustochytrids based on their polyunsaturated fatty acid profiles and comparative analysis of $18 \mathrm{~S}$ rRNA genes. Mar. Biotechnol. 2003, 5, 450-457. [CrossRef] [PubMed]

11. Burja, A.M.; Radianingtyas, H.; Windust, A.; Barrow, C.J. Isolation and characterization of polyunsaturated fatty acid producing Thraustochytrium species: Screening of strains and optimization of omega-3 production. Appl. Microbiol. Biotechnol. 2006, 72, 1161-1169. [CrossRef] [PubMed]

12. Gomathi, V.; Saravanakumar, K.; Kathiresan, K. Production of polyunsaturated fatty acid (DHA) by mangrove-derived Aplanochytrium sp. Afr. J. Microbiol. Res. 2013, 7, 1098-1103.

13. Zeng, Y.; Ji, X.J.; Lian, M. Development of a temperature shift strategy for efficient docosahexaenoic acid production by a marine fungoid protist, Schizochytrium sp. HX-308. Appl. Biochem. Biotechnol. 2011, 164, 249-255. [CrossRef] [PubMed]

14. Jing, L.; Liu, R.; Chang, G. A strategy for the highly efficient production of docosahexaenoic acid by Aurantiochytrium limacinum, SR21 using glucose and glycerol as the mixed carbon sources. Bioresour. Technol. 2015, 177, 51-57. 
15. Zhang, L.; Zhao, H.; Lai, Y. Improving docosahexaenoic acid productivity of Schizochytrium sp. by a two-stage AEMR/shake mixed culture mode. Bioresour. Technol. 2013, 142, 719-722. [CrossRef] [PubMed]

16. Kalil, S.J.; Maugeri, F.; Rodrigues, M.I. Response surface analysis and simulation as a tool for bioprocess design and optimization. Process Biochem. 2000, 35, 539-550. [CrossRef]

17. Wu, S.T.; Lin, L.P. Application of response surface methodology to optimize docosahexaenoic acid production by Schizochytrium sp. S31. J. Food Biochem. 2003, 27, 127-139. [CrossRef]

18. Muthukumar, M.; Mohan, D.; Rajendran, M. Optimization of mix proportions of mineral aggregates using Box Behnken design of experiments. Cem. Concr. Compos. 2003, 25, 751-758. [CrossRef]

19. Lewis, T.E.; Nichols, P.D.; Mcmeekin, T.A. Sterol and squalene content of a docosahexaenoic-acid-producing thraustochytrid: Influence of culture age, temperature, and dissolved oxygen. Mar. Biotechnol. 2001, 3, 439-447. [CrossRef] [PubMed]

20. Elrazak, A.A.; Ward, A.C.; Glassey, J. Response surface methodology for optimising the culture conditions for eicosapentaenoic acid production by marine bacteria. J. Ind. Microbiol. Biotechnol. 2013, 40, 477-487. [CrossRef] [PubMed]

21. Yaguchi, T.; Tanaka, S.; Yokochi, T.; Nakahara, T.; Higashihara, T. Production of high yields of docosahexaenoic acid by Schizochytrium sp. strain SR21. J. Am. Oil Chem. Soc. 1997, 74, 1431-1434. [CrossRef]

22. Morita, E.; Kumon, Y.; Nakahara, T.; Kagiwada, S.; Noguchi, T. Docosahexaenoic acid production and lipid-body formation in Schizochytrium limacinum SR21. Mar. Biotechnol. 2006, 8, 319-327. [CrossRef] [PubMed]

23. Jain, R.; Raghukumar, S.; Sambaiah, K.; Kumon, Y.; Nakahara, T. Docosahexaenoic acid accumulation in thraustochytrids: Search for the rationale. Mar. Biol. 2007, 151, 1657-1664. [CrossRef]

24. Raghukumar, S. Thraustochytrid marine protists: Production of PUFAs and other emerging technologies. Mar. Biotechnol. 2008, 10, 631-640. [CrossRef] [PubMed]

25. Zhou, P.P.; Lu, M.W.; Yu, L.J. Microbial production of docosahexaenoic acid by a low temperature-adaptive strain Thraustochytriidae sp. Z105: Screening and optimization. J. Basic Microbiol. 2010, 50, 380-387. [CrossRef] [PubMed]

26. Ethier, S.; Woisard, K.; Vaughan, D. Continuous culture of the microalgae Schizochytrium limacinum on biodiesel-derived crude glycerol for producing docosahexaenoic acid. Bioresour. Technol. 2011, 102, 88-93. [CrossRef] [PubMed]

27. Ren, L.J.; Ji, X.J.; Huang, H. Development of a stepwise aeration control strategy for efficient docosahexaenoic acid production by Schizochytrium. sp. Appl. Microbiol. Biotechnol. 2010, 87, 1649-1656. [CrossRef] [PubMed]

28. Jiang, Y.; Chen, F. Effects of medium glucose concentration and $\mathrm{pH}$ on docosahexaenoic acid content of heterotrophic Crypthecodinium cohnii. Process Biochem. 2000, 35, 1205-1209. [CrossRef]

29. Furlan, V.J.M.; Paulo, M.D.C.; Batista, I.; Bandarra, N.M. Effect of the concentration of glucose in the docosahexaenoic acid (DHA) production by Thraustochytrium sp. ATCC 26185. Adv. J. Food Sci. Technol. 2012, 4, 257-264.

30. Furlan, V.J.M.; Paulo, M.D.C.; Maus, V.W.; Ferreira, J.; Batista, I.; Bandarra, N.M. Production of docosahexaenoic acid (DHA) from Thraustochytrium sp. ATCC 26185 using different nitrogen concentrations. Bol. Cent. Pesqui. Process. Aliment. 2014, 32. [CrossRef]

31. Weete, J.D.; Kim, H.; Gandhi, S.R.; Wang, Y.; Dute, R. Lipids and ultrastructure of Thraustochytrium sp. ATCC 26185. Lipids 1997, 32, 839-845. [CrossRef] [PubMed]

32. Palvannan, T.; Sathishkumar, P. Production of laccase from Pleurotus florida NCIM 1243 using plackett-burman design and response surface methodology. J. Basic Microbiol. 2010, 50, 325-335. [CrossRef] [PubMed]

33. Sharma, P.; Singh, L.; Dilbaghi, N. Optimization of process variables for decolorization of Disperse Yellow 211 by Bacillus subtilis using Box-Behnken design. J. Hazard. Mater. 2009, 164, 1024-1029. [CrossRef] [PubMed]

34. Wu, S.T.; Yu, S.T.; Lin, L.P. Effect of culture conditions on docosahexaenoic acid production by Schizochytrium sp. S31. Process Biochem. 2005, 40, 3103-3108. [CrossRef]

35. Kumar, A.; Prasad, B.; Mishra, I.M. Optimization of process parameters for acrylonitrile removal by a low-cost adsorbent using Box-Behnken design. J. Hazard. Mater. 2008, 150, 174-182. [CrossRef] [PubMed]

Sample Availability: Samples of the compound not are available from the authors. 